\title{
The Reverend Professor Fergus J. Macartney 7 December, 1940-29 November, 2005
}

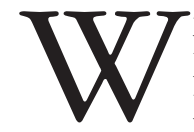
ith the Passing of Fergus Macartney, British and World paediatric cardiology has lost one of its main innovators and practitioners. Fergus was born in December, 1940, in the dark days of the beginning of the Second World War. His father was a clergyman working for the Church Missionary Society, and he was based in Uganda at the time of Fergus' birth. Fergus lived in Uganda until he was 7, with his early education provided by his mother, who came from a very academic background. On his return to the United Kingdom, following a period at preparatory school, he entered University College School in London, from where he obtained a scholarship to Queens' College, Cambridge. It took quite some time for him to be persuaded to wear shoes subsequent to his return to England, and this penchant for unconventionality was one he retained for the rest of his life. Following a distinguished undergraduate career in Cambridge, where he also met and married Jackie, his life-long supporter, he studied medicine at St Thomas' Hospital. Subsequent to qualification, he trained first in adult cardiology, but had determined to enter the newly emerging specialty of paediatric cardiology. With this in mind, he spent a formative year at the Mayo Clinic, at the time perhaps the foremost World centre dealing with childhood problems of the heart. He retained the friendship and support of those with whom he worked in Minnesota for the rest of his life, notably Doug Mair, his first mentor, and Umberto Squarcia, subsequently the Chief in Parma, but a fellow in Rochester at the same time as Fergus. When he returned to the United Kingdom, he was appointed as consultant in Paediatric Cardiology in Leeds, at the remarkably young age of 29. He was fortunate to be associated with a second mentor at Leeds, namely Olive Scott, and together they built an excellent small department, incorporating the necessary surgical experience through the collaboration of Philip Deverall. Thus, when the opportunity arose, in 1975, to take the newly created Chair of Paediatric Cardiology at Great Ormond Street, he was ideally positioned to assume the role of academic leader. His achievements were huge. Not least amongst them was the support given to Jane Somerville when she proposed establishing a World Congress in Paediatric Cardiology. The growth of this congress itself is testament to his vision and intellectual rigour. Overall, his tenure of the chair at Great Ormond Street marked a period of unprecedented achievement. In partnership with his colleagues at The Brompton and Guy's Hospitals, he was instrumental in developing the system for classification and description that is now used throughout most of the world. This same team of colleagues also started their collaborative work in editing a textbook of Paediatric Cardiology, a task they soon discovered to be much harder than initially thought. The book did eventually appear, and has now passed through its second edition, receiving warm praise for its content and uniformity of style and presentation. Perhaps his most important achievement, however, was to work with the talented fellows who flocked to London during the 1980s to establish the "road map" for diagnosis of congenital cardiac malformations, using the newly developed technique of cross-sectional echocardiography. These were heady and exciting times, and during the period of tenure of John Deanfield, Jeff Smallhorn, and Jim Huhta, new manuscripts were emerging at a rate of more than one each month.

From the earliest stages, Fergus had seen the opportunity for using computers in clinical practice, not only for coding and classification, but also for decisionmaking. In these works, he was ably assisted by Kate Bull, who rapidly became his Senior Lecturer, and together they established important links with David Spiegelhalter. By this time, he was in demand worldwide as a lecturer and organiser. The courses he organised at Cambridge on behalf of the British Council were integral in introducing many European and International practitioners to the intricacies of congenital cardiac disease as seen in the infant and neonate. His hallmark throughout this period, nonetheless, was to be his own man. He attended an audience with the Pope in open neck shirt and sandals (Figure), yet visited the Rome Opera the same evening in suit, shirt, tie and shoes for a performance of Parsifal, paying due homage to Richard Wagner, one of his favourite composers. 
He realised at this time that, if he was to realise fully the value of the computer, he would need to upgrade his mathematical expertise. To this end, he was granted sabbatical leave, which he chose to take in Cambridge. Following this sabbatical leave, he returned initially to Great Ormond Street, whilst continuing to live in Cambridge. Then, determined to follow the lead of his strongly held Christian beliefs, and demonstrating yet again his unconventionality, he forsook clinical medicine and became an ordained minister. For a short period, he became a chaplain at Lee Abbey, in South West England, exercising his gifts for both preaching and counselling. The lure of paediatric cardiology, nonetheless, remained strong, and we were all delighted when he returned to the clinical arena in 1991, accepting the Chair of Paediatric Cardiology in the University of Amsterdam. Sadly, the time of taking up the Chair in Holland corresponded with the first appearance of Parkinson's disease, albeit that even he did not recognise the first signs of illness. His affliction, however, prevented him from achieving the potential on offer in Amsterdam, particularly since this demanded that he fight his corner on behalf of his colleagues in committees conducted in the Dutch language. He was relieved, therefore, when the authorities in Amsterdam recognised the extent of his growing disability, and granted him permission to return in retirement to Cambridge. The disease,

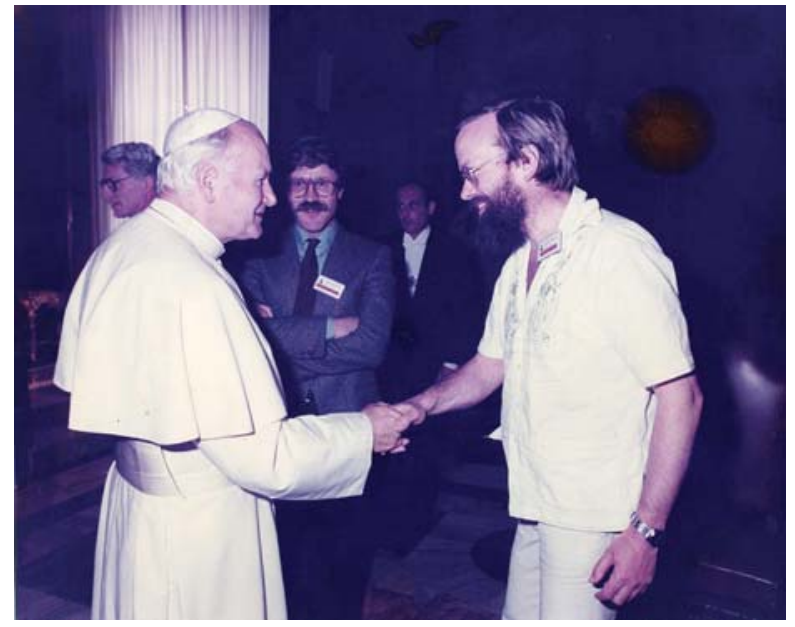

unfortunately, progressed rapidly, and his final years were far from easy, although he bore his difficulties with fortitude, again bolstered by his unswerving Christian belief. He is survived by Jackie, and his three daughters, all of whom are involved in the caring professions. In concert with the rest of us, his family will take comfort in knowing that his contributions remain enshrined in his many books and publications, which for sure will retain their relevance for many years to come.

Robert H. Anderson, Rebecca Winfrey 